\title{
Editorial
}

\section{Chagas disease centennial anniversary celebration: historical overview and prospective proposals aiming to maintain vector control and improve patient prognosis - a permanent challenge}

The organisation of the "International Symposium on the Centennial of the Discovery of Chagas Disease" (Rio de Janeiro, Brazil) is among the actions initiated by the Oswaldo Cruz Foundation to celebrate the centenary of the discovery of American trypanosomiasis by Carlos Chagas, in 1909. This Symposium comes at a time when discussions on new approaches for the control of this devastating disease are needed and it creates a unique opportunity for up-to-date presentations and debates from an assembly of eminent researchers from different countries. More than 650 participants, presenting about 300 posters, as well as 52 lectures and conferences, are expected at this meeting. This congregation of leading researchers gives us an historical opportunity to revisit the unique achievement of Carlos Chagas when he discovered a new nosology, as well as its vector and causative agent, the haemoflagellate protozoan Trypanosoma cruzi. He also described the entire life cycle and the pathology caused by this infectious agent. Furthermore, the question-based lectures and conferences create the propitious scenario for discussion of the plethora of information on the disease and for the reflection on proposals that contribute significantly to the advancement of knowledge in the field of Chagas disease, keeping in mind the importance of vector control maintenance and overall patient care, including early diagnosis, adequate follow up and therapy, aiming to improve both prognosis and quality of life.

Here, we wish to thank the participants for their efforts and our colleagues for taking part in the discussions and presenting their findings during the lectures and round tables. Further, we thank the Scientific Committee, for the great suggestions that helped us to build this meeting, as well as all the referees that acted promptly to revise the manuscripts published herein, and the abstracts presented in the poster format during the Symposium. Furthermore, we are also in debt to the Oswaldo Cruz Foundation, ABRASCO, Fiotec, FAPERJ, CNPq and CAPES, for their support.

The "International Symposium on the Centennial of the Discovery of Chagas Disease" is an opportunity to revisit the scenario of Chagas disease prior to its discovery, the discovery context, and the successes and the challenges to be faced in controlling this disease. American trypanosomiasis, later named Chagas disease in tribute to the discovery by Dr. Carlos Chagas (1909), is a prominent, debilitating infection of high medical importance. Carlos Chagas' discovery had a major impact on the understanding of several medical conditions observed in the Americas that had no previous explanations. However, the existence of American trypanosomiasis precedes its description and recognition by the scientific community. Indeed, mummies dated at 9,000 BP ( 7,000 BC) to $450 \mathrm{BP}(\sim 1,500 \mathrm{AD})$ were identified in different areas of Latin America as infected and clinically afflicted, with megacolon (Araújo et al. 2009). The Spanish and Portuguese conquest and colonisation of the Americas as well as the commerce among the newly established human conglomerations led to intense human migrations, contributing to the occupation of new ecological niches and dissemination of Triatoma infestans, the triatomine that became the main vector of Chagas disease in Brazil and most Latin American countries (Dias 2007, 2009). The ever-increasing number of afflicted individuals led to the inevitable identification by the trained and questioning eye of Carlos Chagas of the new nosology, as well as its vector and causative agent, the haemoflagellate protozoan T. cruzi (Chagas 1909).

Although a detailed global incidence or prevalence of the infection and disease by an updated epidemiological and serological inquiry is lacking, Dias (2007) estimates that the number of infected individuals in Latin America ranges from 12-14 million people in 18 endemic countries. Furthermore, several hundred thousand afflicted individuals might be living in North America, Europe and other countries as a result of migration by people to these areas in search of a better life (Coura 2007, Schmunis 2007). These numbers indicate the social importance of Chagas disease and the public health challenges that remain 100 years after its discovery.

The chemical control of the main Chagas disease vector (T. infestans) as a result of the Initiative of the South Cone, associated with blood bank compulsory screening, led to a remarkable decline in acute case numbers in all countries participating in this initiative (Dias 2009, Moncayo \& Silveira 2009). Recent data from the Brazilian Ministry of Health confirmed the occurrence of 2,476 cases (1,603 vectorial, 16 transfusional and 7 transplacentary transmission, as well as 850 cases of a non-identified form of transmission) of acute Chagas disease from 2001-2006, with 95 deaths (http://dtr2004.saude.gov.br). Although several Latin American countries, including Brazil, received the PAHO/WHO certification of interruption of vectorial transmission via T. infestans in 2006 (Moncayo \& Silveira 2009), attention should be given to the new cases of Chagas disease that occur due to contaminated food and beverages in endemic areas. Additionally, the geographical distribution of confirmed vector-borne cases of Chagas disease in all Brazilian regions is required, with special attention to the Amazon (Figure), painting a distressing picture. 
Furthermore, recognition of the epidemiological importance of sylvatic and semi-domiciliated vectors indicates the requirement for permanent surveillance in order to avoid the resurgence of acute Chagas disease in our territory (Coura 2007, Guhl et al. 2009, Lazzari \& Lorenzo 2009).

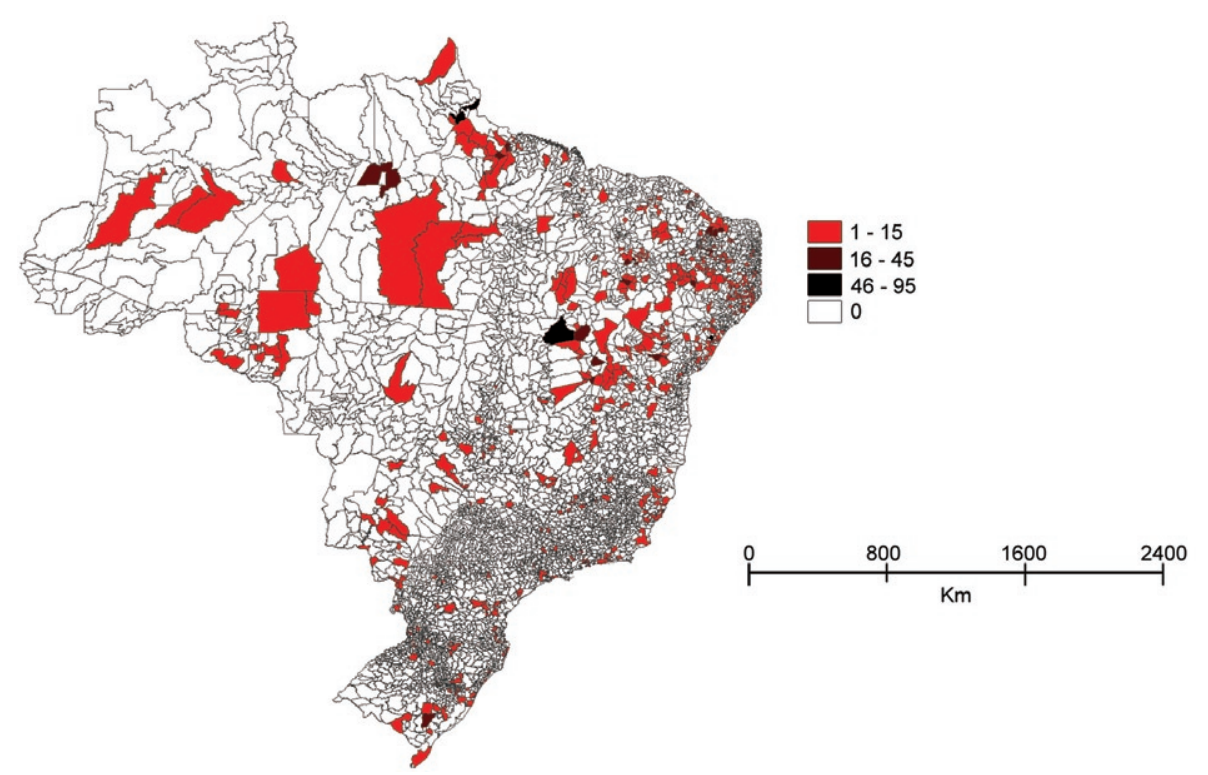

The geographical spread of the confirmed vector-borne cases of Chagas disease in Brazil notified in the period 2001-2006. The confirmed vector-borne cases of Chagas disease were classified in four categories, according to the numbers of notified cases in a city: the white-painted areas indicate absence of notification, the red-painted areas indicate cities with 1-15 notified cases, brown-painted areas show cities with 16-45 cases and the black-painted areas indicate cities with 46-95 confirmed cases. The data were obtained from Brazilian Health Ministry site (http:// dtr2004.saude.gov.br/sinanweb/), accessed March $9^{\text {th }} 2009$.

In summary, it is time to commemorate both the unique features in the science and medicinal history of Carlos Chagas and the currently successful main vector control and decline of new acute cases, as described above. However, it is imperative to remember that we still face other challenges, including the following urgent needs:

(i) to develop strategies for maintaining sustainable and integrated surveillance in areas that display diverse epidemiological patterns, allowing the identification of priority areas for intervention;

(ii) to guarantee patients adequate global care and access to available therapies;

(iii) to improve the diagnostic tools for early (parasitological, serological) diagnosis of the infection;

(iv) to identify and validate prognostic markers for disease progress to support rational interventions;

(v) to design and search for new selective prophylactic and therapeutic tools, based on T. cruzi and/or human genomic and proteomic information, guaranteeing their assessment in clinical studies, as well as identifying new options (i.e., low costs, oral applications, protective against widespread isolates of the parasites etc.) that are effective during the chronic phase (in the case of a trypanocidal drug) with low toxicity to the patient and

(vi) to support research aimed increasing our knowledge regarding the biochemical, biological and molecular machinery involved in host/parasite interactions and the pathophysiological mechanisms operating in disease progression. This would allow the generation of new approaches, including cell therapy, immunoregulation and vaccines, targeted at interrupting disease development.

\author{
Joseli Lannes-Vieira \\ Maria de Nazaré Correia Soeiro \\ Rodrigo Corrêa-Oliveira \\ Tania Cremonini de Araújo-Jorge
}




\section{ACKNOWLEDGMENTS}

To Dr. Andreia Dantas, MSc. Alexandre Fernandes (Programa Integrado de Doença de Chagas) and MSc. Ana Paula da Costa Resendes (Escola Nacional de Saúde Pública Sérgio Arouca-Fiocruz) in Figure construction based on Health Ministry data (http://tr2004.saude.gov.br/sinanweb/tabnet/ dh?sinan/chagas/bases/chagasbr.def).

\section{REFERENCES}

Araújo A, Jansen AM, Reinhard K, Ferreira LF 2009. Paleoparasitology of Chagas disease: A review. Mem Inst Oswaldo Cruz 104(Suppl. I): 9-16.

Chagas RJ 1909. Nova tripanosomiase humana. Estudos sobre a morfolojia e o ciclo evolutivo do Schizotrypanum cruzi n.g., n.sp., ajente etiolojico de nova entidade morbida do homem. Mem Inst Oswaldo Cruz 1: 159-218.

Coura JR 2007. Chagas disease: what is known and what is needed-a background article. Mem Inst Oswaldo Cruz 102: 113-122.
Dias JC 2007. Southern Cone Initiative for the elimination of domestic populations of Triatoma infestans and the interruption of transfusional Chagas disease. Historical aspects, present situation and perspectives. Mem Inst Oswaldo Cruz 102: 11-18.

Dias JC 2009. Elimination of Chagas disease transmission: perspectives. Mem Inst Oswaldo Cruz 104 (Suppl. I): 41-45.

Guhl F, Pinto N, Aguilera G 2009. Sylvatic triatominae: a new challenge in vector control transmission. Mem Inst Oswaldo Cruz 104 (Suppl. I): 71-75.

Lazzari CR, Lorenzo MG 2009. Exploiting triatomine behaviour: alternative perspectives for their control. Mem Inst Oswaldo Cruz 104 (Suppl. I): 65-70.

Moncayo A, Silveira AC 2009. Current epidemiological trends for Chagas disease in Latin America and future challenges in epidemiology, surveillance and health policy. Mem Inst Oswaldo Cruz 104(Suppl. I): 17-30.

Schmunis GA 2007. Epidemiology of Chagas disease in non-endemic countries: the role of international migration. Mem Inst Oswaldo Cruz 102: 75-85. 